\title{
As diferenças microclimáticas entre as tipologias de floresta urbana e os dados registrados pela estação meteorológica oficial
}

The microclimatic differences between the typologies of urban forests and the data registered by the official meteorological station

\author{
A. Martini ${ }^{1 *}$; D. Biondi ${ }^{1}$; A. C. Batista ${ }^{1}$ \\ ${ }^{l}$ Departamento de Ciências Florestais, Laboratório de Paisagimo, Setor de Ciências Agrárias, Universidade Federal \\ do Paraná, 80210-170, Curitiba-PR, Brasil \\ *martini.angeline@gmail.com
}

(Recebido em 20 de fevreiro de 2017; aceito em 11 de abril de 2017)

\begin{abstract}
As cidades precisam ser readequadas para proporcionar melhores condições ambientais a seus habitantes, incluindo conforto térmico. A presença de vegetação nas cidades é uma importante ferramenta para criar microclimas mais agradáveis. Assim, o objetivo desta pesquisa foi analisar as diferenças microclimáticas entre as tipologias de floresta urbana e os dados registrados pela estação meteorológica oficial de CuritibaPR. Para isso foram selecionadas três áreas de diferentes tipologias de floresta urbana na cidade de CuritibaPR: Remanescente Florestal, Área Verde Antiga, Área Verde Moderna, Arborização de Ruas e Árvore Isolada. A partir do método de pontos fixos foram coletados dados de temperatura e umidade relativa do ar para analisar o microclima de cada área. Os resultados indicam que a temperatura no Remanescente Florestal e Área Verde Moderna apresentaram médias inferiores às registradas pela estação oficial no verão. Nas demais tipologias a temperatura média foi maior do que na estação oficial. Observou-se também, que a diferença de temperatura entre as áreas foi mais acentuada durante a noite. Conclui-se que a determinação da diferença microclimática entre as tipologias de floresta urbana e os dados registrados pela estação oficial pode ser uma ferramenta de grande importância para o planejamento e gestão das florestas urbanas.

Palavras-chave: arborização urbana, clima urbano, remanescente flroestal.
\end{abstract}

Cities need to be adapted to provide better environmental conditions for their inhabitants, including thermal comfort. The presence of vegetation in cities is an important tool to create more pleasant microclimates. Thus, the main goal of this research was to analyze the microclimatic differences between the typologies of urban forest and the data recorded by the official meteorological station of Curitiba-PR. For this, three areas of different types of urban forest were selected in the city of Curitiba-PR: Remaining Forest, Old Green Area, Modern Green Area, Street Trees and Isolated Tree. From the fixed point method data were collected on temperature and relative humidity of the air to analyze the microclimate of each area. The results indicate that the temperature in the Remaining Forest and the Modern Green Area presented averages lower than those recorded by the official season in the summer season. In the other typologies the average temperature was higher than in the official season. It was also observed that the temperature difference between the areas was more pronounced at night. It is concluded that the determination of the microclimatic difference between the typologies of urban forest and the data recorded by the official station can be a tool of great importance for the planning and management of urban forests.

Keywords: afforestation, urban climate, remnant forest.

\section{INTRODUÇÃO}

As mudanças climáticas têm causado impactos sobre os sistemas naturais e humanos em todos os continentes e oceanos [1]. O aumento da temperatura global reconhecido durante as últimas décadas é relevante, uma vez que as temperaturas mais elevadas contribuem para ondas mais intensas de calor, secas e tempestades, a elevação do nível do mar e inundações destrutivas; afetando a segurança alimentar e a habitabilidade de regiões litorâneas, além da composição de espécies nos ecossistemas locais [2].

As áreas urbanas concentram muitos dos riscos globais das mudanças climáticas como estresse por calor, precipitações extremas, inundações, deslizamentos de terra, poluição do ar, seca e escassez de água [1]. Ainda, segundo os relatórios do IPCC, os riscos são maiores para aqueles que 
não possuem infraestruturas e serviços essenciais ou que vivem em moradias de baixa qualidade e em áreas expostas [1].

Muitos habitantes das cidades em todo o mundo sofrem de problemas de saúde e desconforto causados por sobreaquecimento das zonas urbanas, havendo evidências convincentes de que esses problemas serão intensificados pela mudança climática global [3]. Os problemas relacionados ao calor são uma questão importante em muitas áreas urbanas do mundo, principalmente porque deve reduzir a demanda de energia para aquecimento e aumentar a demanda de energia para refrigeração nos setores residenciais e comerciais [1].

O clima urbano provoca efeitos que são sentidos cada vez mais pela população, pois gera um desconforto térmico que afeta diretamente a vida dos habitantes [4]. Assim, para garantir a sobrevivência da vida na Terra é preciso que as cidades trabalhem unidas na proteção do ambiente [5]. Dentre as várias opções para fornecer refrigeração às cidades, a melhor já documentada é a criação de parques urbanos e espaços verdes que têm o potencial de fornecer ambientes termicamente confortáveis e reduzir a vulnerabilidade ao estresse térmico [3].

A capacidade única que a vegetação apresenta de controlar muitos dos efeitos adversos do meio urbano contribui para uma significativa melhoria da qualidade de vida [6,4]. Segundo Gartland (2010) [7], esse benefício microclimático proporcionado pela vegetação se deve a dois fatores principais: sombreamento e evapotranspiração. As sombras produzidas pelas árvores para edifícios, pavimentos e pessoas as protegem do calor do sol, mantendo essas superfícies mais frescas e reduzindo o calor transferido por elas para o ar acima. Já a evapotranspiração utiliza a energia solar para evaporar a água, o que evita que essa energia seja usada para produzir calor e aquecer a cidade, mantendo as temperaturas do ar mais baixas durante o dia.

Embora comprovado este efeito, a maioria das cidades ainda não são projetadas para minimizar tais problemas climáticos [3]. Estudos sobre clima urbano ainda precisam ser estimulados, não apenas pela necessidade de adquirir informações sobre os inúmeros efeitos da urbanização, mas também para auxiliar nas decisões de planejamento ambiental e readequação das áreas urbanas [8].

Assim, o objetivo desta pesquisa foi analisar as diferenças microclimáticas entre as tipologias de floresta urbana e os dados registrados pela estação meteorológica oficial de Curitiba-PR, de modo a contribuir com o planejamento e gestão das florestas urbanas na cidade.

\section{MATERIAL E MÉTODOS}

A pesquisa foi realizada na cidade de Curitiba, Paraná, localizada a 934,6 m de altitude média, sendo que o marco zero do município está situado a $25^{\circ} 25^{\prime} 40^{\prime \prime} \mathrm{S}$ e $49^{\circ} 16^{\prime} 23^{\prime \prime}$ W. Segundo a classificação de Köppen, o clima é do tipo Cfb, subtropical úmido, mesotérmico, sem período seco, com verões frescos e invernos com geadas frequentes e ocasional precipitação de neve [9]. O verão é ameno (com temperaturas médias de $\left.19,7^{\circ} \mathrm{C}\right)$ e o inverno moderado $\left(13,4^{\circ} \mathrm{C}\right.$ em média) com alguns dias mais rigorosos. A precipitação média anual é de $1.419,91 \mathrm{~mm}$ com um período de estiagem, não fixo, entre o outono e o inverno [9].

Foram selecionadas áreas que representassem as tipologias de floresta urbanas mais frequentes na cidade: Remanescente Florestal; Área Verde Antiga (agrupamentos de árvores implantadas com paisagismo eclético); Área Verde Moderna (agrupamentos de árvores implantadas com paisagismo moderno); Arborização de Ruas (agrupamento de árvores contínuo que acompanha o sistema viário); Árvore Isolada (indivíduo arbóreo único, plantado no sistema viário de forma espaçada).

Para proporcionar representatividade, foram selecionadas três áreas para cada tipologia de floresta urbana, totalizando 15 locais de monitoramento restritos à porção central da cidade (Figura 1): Parque Natural Municipal Barigüi, Bosque Gutierrez e Bosque João Paulo II (Remanescente Florestal); Passeio Público, Praça Eufrásio Correia e Praça Carlos Gomes (Área Verde Antiga); Praça Nossa Senhora de Salette, Praça Alfredo Andersen e Jardinete Henrique Knopholz (Área Verde Moderna); Rua Ângelo Lopes, Rua Brigadeiro Franco e Rua Guaratuba (Arborização de Ruas); Lagerstroemia indica L. localizada na Rua Sant'Ana ${ }^{\circ}$. 395, Lafoensia pacari A.St.-Hil. localizada na Rua Brasílio Itiberê ${ }^{\circ}$. 295 e Handroanthus chrysotrichus (Mart. ex A.DC.) Mattos localizado na Rua Cel. João da Silva Sampaio nº 648 (Árvore Isolada). 


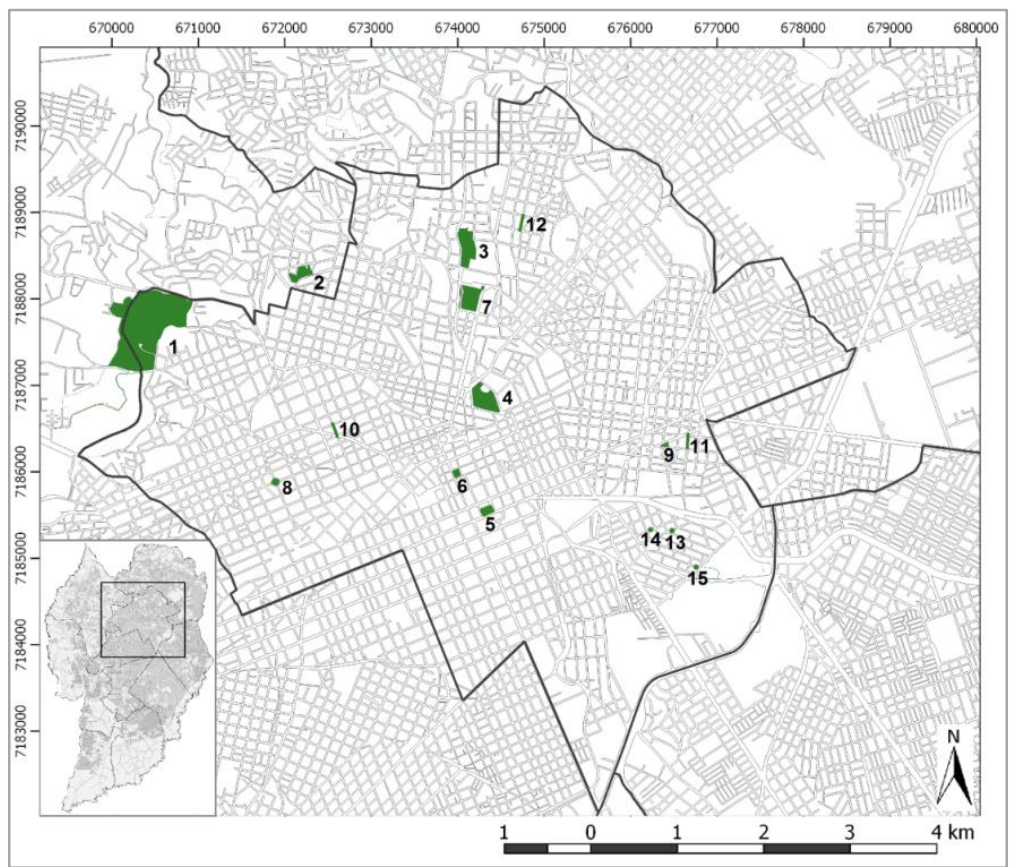

Figura 1: Locais de monitoramento para análise do microclima na cidade de Curitiba, Paraná. Legenda: 1 - Parque Barigüi; 2 - Bosque Gutierrez; 3 - Bosque João Paulo II; 4 - Passeio Público; 5 - Praça Eufrásio Correia; 6 - Praça Carlos Gomes; 7- Praça Nossa Senhora de Salette; 8 - Praça Alfredo Andersen; 9 Jardinete Henrique Knopholz; 10 - Rua Brigadeiro Franco; 11 - Rua Ângelo Lopes; 12 - Rua Guaratuba; 13 - Lagerstroemia indica; 14 - Lafoensia pacari; 15 - Handroanthus chrysotrichus.

O microclima das diferentes áreas foi analisado com base nos dados meteorológicos coletados a partir do método de pontos fixos. As variáveis meteorológicas coletadas com registradores data logger modelo Hobo® RH \& Temp., da marca Onset foram temperatura $\left({ }^{\circ} \mathrm{C}\right)$ e umidade relativa do ar $(\%)$. Os registradores Hobo ${ }^{\circledR}$ foram instalados no centro de cada área de interesse, em mini abrigos meteorológicos a $4 \mathrm{~m}$ do solo. Os mini abrigos foram confeccionados com uma seção de tubo PVC de $150 \mathrm{~mm}$ de comprimento e $100 \mathrm{~mm}$ de diâmetro, com aberturas nas laterais e revestidos externamente com papel alumínio, fechados por duas tampas. Foram fixados no tronco das árvores na posição vertical, com auxílio de uma fita abraçadeira de nylon.

O monitoramento das variáveis meteorológicas foi realizado simultaneamente entre as quinze áreas selecionadas, nos dias 20 a 22 de fevereiro de 2014 (verão) e 28 a 30 de julho de 2014 (inverno). As datas foram definidas com base no histórico climático da cidade. Por questões de segurança e outras possíveis interferências humanas, a coleta das variáveis meteorológicas teve duração de 48 horas, com tomada contínua em intervalos de 1 minuto, iniciando-se às 12:00 h e totalizando 2882 leituras. Os dias foram caracterizados como de céu limpo e sem previsão de chuva.

Os dados meteorológicos coletados foram descarregados no computador e transferidos para o programa Excel, onde foram processados. Realizou-se uma análise das diferenças encontradas entre as tipologias de floresta urbana, para os valores médios, máximos e mínimos. Para isso, foi preciso utilizar os dados pareados a cada hora, onde os valores encontrados nas diferentes tipologias foram subtraídos dos valores registrados pela estação oficial do Sistema Meteorológico do Paraná (SIMEPAR).

Embora os dados oficiais sejam coletados com outros equipamentos e em alturas diferentes, optou-se por essa comparação devido à disponibilidade dessas informações, visado à aplicação prática da pesquisa, uma vez que grande parte das cidades possuem suas estações oficiais. Além disso, segundo a WMO (2008) [10], existe uma flexibilidade para coletar dados meteorológicos em áreas urbanas em alturas maiores daquelas coletadas na altura padrão, sem necessidade de correção de dados. 
Desta forma, obteve-se a diferença microclimática proporcionada por cada uma das tipologias de floresta urbana no verão e inverno, bem como em cada período do dia, sendo os períodos divididos em dia, compreendendo os horários entre 7:00 e 18:00 h; e noite entre as 19:00 e 6:00 h.

\section{RESULTADOS E DISCUSSÃO}

A diferença microclimática entre as tipologias, calculada com base na diferença de cada área para a estação oficial do SIMEPAR (Tabela 1), permite analisar quantitativamente o comportamento das tipologias no verão, inverno e em cada período do dia.

Tabela 1: Diferença microclimática proporcionada por cada tipologia de floresta urbana no verão e inverno e por período em Curitiba, Paraná.

\begin{tabular}{|c|c|c|c|c|c|c|c|}
\hline \multirow{2}{*}{\multicolumn{2}{|c|}{$\begin{array}{l}\text { Tipologias de } \\
\text { Floresta Urbana } \\
\end{array}$}} & \multicolumn{3}{|c|}{ Verão } & \multicolumn{3}{|c|}{ Inverno } \\
\hline & & Máx & Mín & Média & Máx & Mín & Média \\
\hline \multicolumn{8}{|c|}{ Temperatura $\left({ }^{\circ} \mathrm{C}\right)$} \\
\hline \multirow{3}{*}{$\begin{array}{c}\text { Remanescente } \\
\text { Florestal }\end{array}$} & Dia & 2,63 & $-0,27$ & 0,18 & 2,03 & $-0,51$ & $-0,05$ \\
\hline & Noite & 7,14 & 1,27 & 2,35 & 3,31 & $-0,82$ & 0,61 \\
\hline & Total & 2,63 & 0,57 & 1,18 & 2,03 & $-0,82$ & 0,25 \\
\hline \multirow{3}{*}{$\begin{array}{l}\text { Área Verde } \\
\text { Antiga }\end{array}$} & Dia & 1,71 & $-1,76$ & $-1,36$ & 1,29 & -1 , & $-0,75$ \\
\hline & No & 6,36 & $-0,33$ & 1,29 & 2,60 & $-1,11$ & 0,06 \\
\hline & Tot & & $-1,03$ & $-0,15$ & 1,29 & $-1,11$ & $-0,38$ \\
\hline \multirow{3}{*}{$\begin{array}{l}\text { Área Verde } \\
\text { Moderna }\end{array}$} & Di & 22 & $-1,48$ & $-1,07$ & ,45 & $-0,87$ & $-0,51$ \\
\hline & $\mathrm{N}$ & 6,77 & 0,16 & 1,77 & 2,92 & $-1,06$ & 0,23 \\
\hline & Tot & 22 & $-0,54$ & 0 , & 1,45 & $-1,06$ & $-0,17$ \\
\hline \multirow{3}{*}{$\begin{array}{c}\text { Arborização } \\
\text { de Ruas }\end{array}$} & $\mathrm{D}$ & 0,9 & $-1,84$ & $-1,97$ & 0,70 & $-0,8$ & $-0,90$ \\
\hline & No & 60 & $-0,03$ & 1, & 86 & $-0,94$ & 0,31 \\
\hline & Tot & 0,9 & $-0,73$ & $-0,2$ & 0 & $-0,94$ & $-0,35$ \\
\hline \multirow{3}{*}{ Árvore Isolada } & $\mathrm{D}$ & & $-2,42$ & -2 , & 78 & -0 & $-0,83$ \\
\hline & Noi & 53 & $-0,05$ & 1,41 & 88 & $-0,94$ & 0,24 \\
\hline & To & 20 & $-0,75$ & $-0,67$ & 8 & -0 & $-0,34$ \\
\hline \multicolumn{8}{|c|}{ Umidade relativa $(\%)$} \\
\hline \multirow{3}{*}{$\begin{array}{l}\text { Remanescente } \\
\text { Florestal }\end{array}$} & $\mathrm{Di}$ & 4,91 & 8,77 & 6,53 & $-2,96$ & 3,6 & 0,01 \\
\hline & Noite & & 12,99 & 9,80 & $-3,11$ & 0 & 1,33 \\
\hline & Total & & 8,77 & 8, & $-3,11$ & 3 , & 0,62 \\
\hline \multirow{3}{*}{$\begin{array}{l}\text { Área Verde } \\
\text { Antiga }\end{array}$} & $\mathrm{D}$ & & $-1,78$ & 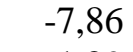 & 8 & -3 & $-6,76$ \\
\hline & & & 4,15 & -1 & & & $-3,75$ \\
\hline & To & 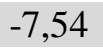 & $-1,78$ & $-4,85$ & $-7,35$ & $-3,93$ & $-5,38$ \\
\hline \multirow{3}{*}{$\begin{array}{l}\text { Área Verde } \\
\text { Moderna }\end{array}$} & $\mathrm{D}$ & $-6,20$ & $-0,39$ & $-5,82$ & $-7,43$ & $-2,05$ & $-5,28$ \\
\hline & Noi & & 8,47 & 3,20 & $-6,38$ & 4,52 & $-3,12$ \\
\hline & To & & $-0,39$ & $-1,68$ & $-6,38$ & $-2,05$ & $-4,29$ \\
\hline \multirow{3}{*}{$\begin{array}{l}\text { Arborização } \\
\text { de Ruas }\end{array}$} & D & $-7,17$ & $-1,82$ & $-8,63$ & $-4,90$ & $-3,84$ & $-5,07$ \\
\hline & No & & 6,43 & 2, & -3 , & 6,73 & $-0,42$ \\
\hline & Tota & $-4,46$ & $-1,82$ & $-3,65$ & $-3,45$ & $-3,84$ & $-2,94$ \\
\hline \multirow{3}{*}{ Árvore Isolada } & Dia & $-8,88$ & $-6,54$ & $-9,57$ & $-1,82$ & $-1,74$ & $-2,73$ \\
\hline & Noite & $-5,47$ & 8,26 & 1,46 & $-0,58$ & 16,7 & 1,85 \\
\hline & Total & $-5,47$ & $-6,54$ & $-4,51$ & $-0,58$ & $-1,74$ & $-0,63$ \\
\hline
\end{tabular}

NOTA: Os valores de temperatura das tipologias foram subtraídos dos valores oficiais, para os valores de umidade relativa o cálculo foi o inverso, os valores oficiais foram subtraídos dos registrados em cada tipologia.

Observa-se no verão, que a temperatura no Remanescente Florestal e Área Verde Moderna apresentaram médias inferiores às registradas pela estação oficial, sendo a diferença de 1,2 e 0,2 ${ }^{\circ} \mathrm{C}$ respectivamente para cada área. Nas demais tipologias a temperatura média foi maior do que na estação oficial, sendo em média $0,1^{\circ} \mathrm{C}$ mais alta na Área Verde Antiga, $0,4^{\circ} \mathrm{C}$ na Arborização de Ruas e $0,7^{\circ} \mathrm{C}$ nos exemplares de Árvore Isolada. No inverno, o Remanescente Florestal apresentou 
temperaturas inferiores (em média $0,2{ }^{\circ} \mathrm{C}$ menor). As demais tipologias apresentaram valores superiores do que os registrados pela estação oficial, sendo em média $0,4{ }^{\circ} \mathrm{C}$ mais elevado na Área Verde Antiga, $0,2{ }^{\circ} \mathrm{C}$ na Área Verde Moderna e $0,3{ }^{\circ} \mathrm{C}$ na Arborização de Ruas e Árvore Isolada.

A temperatura máxima foi menor em todas as tipologias tanto no verão quanto no inverno, sendo a maior diferença média observada no Remanescente Florestal $\left(2,6^{\circ} \mathrm{C}\right)$ e a menor nos exemplares de Árvore Isolada $\left(0,2^{\circ} \mathrm{C}\right)$, ambas no verão. Já as temperaturas mínimas, no verão e inverno, foram maiores nas diferentes tipologias do que na estação oficial, exceto para o Remanescente Florestal no verão, onde a mínima foi $0,6{ }^{\circ} \mathrm{C}$ menor. Para Hasenack et al. (2010) [11], o amortecimento à incidência de energia por parte da vegetação arbórea é o responsável por criar, na camada de ar entre a superfície e o dossel, um microclima com amplitudes térmicas bem inferiores às amplitudes térmicas de áreas mais abertas.

A diferença de temperatura é mais acentuada durante a noite. Pode-se observar em todas as tipologias que a diferença de temperatura máxima durante o dia foi em média $5,1^{\circ} \mathrm{C}$ menor do que à noite no verão e $1,7^{\circ} \mathrm{C}$ no inverno. Para a temperatura mínima, durante o dia a diferença foi menor em $1,8{ }^{\circ} \mathrm{C}$ no verão e maior em $0,1{ }^{\circ} \mathrm{C}$ no inverno.

Com relação à temperatura média, observa-se que os valores durante a noite sempre foram menores nas diferentes tipologias de floresta urbana, sendo que no verão as diferenças de temperaturas durante o dia foram em média $3^{\circ} \mathrm{C}$ maiores do que durante a noite, e no inverno 0,9 ${ }^{\circ} \mathrm{C}$; contrariando afirmações anteriores. Segundo Hamada e Mikami (1994) [12], nas áreas cobertas por grama a temperatura durante o dia é maior do que nas áreas arborizadas devido à radiação direta, mas a noite essa diferença diminui devido o resfriamento da superfície de grama.

A influência direta da vegetação e da permeabilidade do solo na amenização do armazenamento de calor noturno foi verificada por Rocha et al. (2011) [13]. Os autores concluíram que em alguns casos podem ser constatadas temperaturas noturnas mais elevadas em áreas arborizadas do que em áreas mais abertas. Essa retenção ocorre devido à ação da vegetação, que atua como uma barreira contra as correntes de ar. Para Hamada e Ohta (2010) [14], as diferenças no fator de visão do céu e nas propriedades térmicas em relação ao armazenamento de calor é que provocam as diferenças na atenuação da temperatura durante a noite, enquanto que durante o dia, as diferenças de radiação controlam esse efeito.

No Remanescente Florestal a umidade relativa média foi maior do que nos dados registrados pela estação oficial, no verão $\left(8^{\circ} \mathrm{C}\right)$ e inverno $\left(0,6^{\circ} \mathrm{C}\right)$. Nas demais tipologias os valores médios de umidade relativa foram sempre inferiores. No verão, os valores em média foram 4,8 unidades menores na Área Verde Antiga, 1,7 unidades na Área Verde Antiga, 3,6 unidades na Arborização de Ruas e 4,5 unidades nos exemplares de Árvore Isolada. No inverno foi em média 5,4 unidades menores na Área Verde Antiga, 4,3 unidades na Área Verde Moderna, 2,9 unidades na Arborização de Ruas e 0,6 unidades nos exemplares de Árvore Isolada.

Observa-se de um modo geral, que o comportamento da variável umidade relativa é o inverso da temperatura. Segundo Soares e Batista (2004) [15], a umidade relativa do ar apresenta um curso diário inverso ao da temperatura, isto porque a umidade relativa é inversamente proporcional à pressão de saturação de vapor d'água, que por sua vez é diretamente proporcional à temperatura.

No verão a umidade relativa máxima do Remanescente Florestal foi 3,6 unidades mais alta do que nos dados da estação oficial, na Área Verde Antiga foi 7,5 unidades mais baixa, assim como na Área Verde Moderna (4,1 unidades), Arborização de Ruas (4,5 unidades) e Árvore Isolada (5,5 unidades). Já no inverno, a umidade relativa mínima do Remanescente Florestal foi 3,7 unidades mais alta do que nos dados da estação oficial, na Área Verde Antiga foi 3,9 unidades mais baixa, assim como na Arborização de Ruas (3,8 unidades), Área Verde Moderna (2,0 unidades) e Árvore Isolada (1,7 unidades).

A diferença de umidade relativa nas tipologias também foi mais acentuada durante o dia, exceto para o Remanescente Florestal. Pode-se observar em todas as tipologias que a diferença de umidade relativa máxima durante o dia foi em média 1,8 unidades maior do que à noite no verão e $1,0^{\circ} \mathrm{C}$ no inverno. Para a umidade relativa mínima, durante o dia a diferença foi maior em 8,4 unidades no verão e 9,6 unidades no inverno. A diferença de umidade relativa média foi 8,1 unidades maiores durante o dia do que à noite no verão e 3,1 unidades no inverno. Estes resultados corroboram com Fortuniak et al. (2006) [16], que afirmam que na área urbana, geralmente, é verificado maior contraste da umidade relativa do ar durante o dia e mais baixo durante à noite. 
De modo geral é possível afirmar que no verão as diferenças de temperatura e umidade relativa entre as áreas são mais acentuadas do que no inverno. Contudo, verificaram-se variações entre as diferenças microclimáticas apresentadas pelas diferentes tipologias de floresta urbana. Resultado que demonstra como o microclima urbano é complexo e está relacionado com o ambiente externo [17].

\section{CONCLUSÃO}

A diferença microclimática entre as tipologias de floresta urbana e os valores oficiais indica que a temperatura no Remanescente Florestal e Área Verde Moderna apresentaram médias inferiores às registradas pela estação oficial no verão. Nas demais tipologias a temperatura média foi maior do que na estação oficial. Observou-se também, que a diferença de temperatura entre as áreas foi mais acentuada durante a noite. Além disso, no verão as diferenças de temperatura e umidade relativa foram mais acentuadas do que no inverno.

Determinar a diferença microclimática entre as tipologias de floresta urbana e os dados registrados pela estação oficial pode ser uma ferramenta de grande importância para o planejamento das florestas urbanas, permitindo intensificar os benefícios microclimáticos.

A determinação do benefício microclimático proporcionado por cada tipologia de floresta urbana permite adequar os projetos de urbanização, uma vez, que possibilita determinar qual tipologia se torna mais adequada para determinadas situações.

\section{AGRADECIMENTOS}

À Fundação Araucária de Apoio ao Desenvolvimento Científico e Tecnológico do Paraná pelo financiamento à compra dos equipamentos.

\section{REFERÊNCIAS BIBLIOGRÁFICAS}

1. Intergovernmental Panel on Climate Change (IPCC). Mudança do Clima 2014 - Impactos, Adaptação e Vulnerabilidade: sumário para tomadores de decisão. Tradução de: Iniciativa Verde. São Paulo: Iniciativa Verde, 2015. Título Original: Climate Change 2014 - Impacts, Adaptation, and Vulnerability: Summary for Policymakers.

2. Heinl M, Hammerle A, Tappeiner U, Leitinger G. Determinants of urban-rural land surface temperature differences - A landscape scale perspective. Landscape and Urban Planning 2015;134:33-42.

3. Brown RD, Vanos J, Kenny N, Lenzholzer S. Designing urban parks that ameliorate the effects of climate change. Landscape and Urban Planning. 2015;138:118-131.

4. Lima GN. Características do clima urbano de Nova Andradina - MS [dissertação]. , Presidente Prudente: Faculdade de Ciências e Tecnologia, Universidade Estadual Paulista; 2011. 161p.

5. Nascimento DTF, Oliveira IJ. Análise da evolução do fenômeno de ilhas de calor no município de Goiânia/GO (1986 - 2010). Boletim Goiano de Geografia. 2011;31(2):113-127.

6. Volpe-Filik A, Silva LF, Lima AMLP. Avaliação da arborização de ruas do bairro São Dimas na cidade de Piracicaba/SP através de parâmetros qualitativos. Revista da Sociedade Brasileira de Arborização Urbana. 2007;2(1):34-43.

7. Gartland L. Ilhas de calor: como mitigar zonas de calor em áreas urbanas. São Paulo: Oficina de Textos, 2010.

8. Huang L, Li J, Zhao D, Zhu J. A fieldwork study on the diurnal changes of urban microclimate in four types of ground cover and urban heat island of Nanjing, China. Building and Environment 2008;43:7-17.

9. Instituto de Pesquisa e Planejamento Urbano de Curitiba (IPPUC). Desenvolvimento sustentável: indicadores de sustentabilidade de Curitiba - 2010. Curitiba: IPPUC, 2011.

10. World Meteorological Organization (WMO). Guide to meteorological instruments and methods of observation. 7.nd. Geneva: WMO, 2008. Disponível em: <http://www.wmo.int/pages/prog/www/IMOP/ publications/CIMO-Guide/CIMO_Guide- 7th_Edition 2008.html> Acesso em: 31 jul. 2015.

11. Hasenack H, Cordeiro JLP, Hoffmann GS. Macroclima, o clima regional e mesoclima, o clima local. SESC. O clima na Reserva Particular de Patrimônio Natural SESC Pantanal. Rio de Janeiro: SESC; 2010. p.61-90. 
12. Hamada T, Mikami T. Cool island phenomenon in urban green spaces: a case study of Meiji Shrine and Yoyogi Park. Geographical Review of Japan 1994;67:518-529.

13. Rocha LMV, Souza LCL, Castilho FJV. Ocupação do solo e ilha de calor noturna em avenidas marginais a um córrego urbano. Ambiente Construído 2011;11(3):161-175.

14. Hamada S, Ohta T. Seasonal variations in the cooling effect of urban green areas on surrounding urban areas. Urban Forestry \& Urban Greening 2010;9:15-24.

15. Soares RV, Batista AC, Tetto AF. Meteorologia e climatologia florestal. Curitiba: Os autores; 2004. $215 \mathrm{p}$.

16. Fortuniak K, Klysik K, Wibig J. Urban-rural contrasts of meteorological parameters in Lodz. Theoretical and Applied Climatology. 2006;84:91-101.

17. Yahia MY, Johansson E. Urban microclimate and thermal comfort in outdoor spaces in hot dry Damascus. In: Proceedings of the VIII International Conference On Urban Climates; 2012; Dublin - IRL: University College Dublin. 2012. Não paginado. 